\title{
Ion Beam Sputtering in Electric Propulsion Facilities
}

(NASA-TM-105145) ION BSAM SPUTTERING IN

N91-32158 ELECTRIC PROPULSION FACILITIES (NASA) If $P$

James S. Sovey and Michael J. Patterson

Lewis Reseärch Center

Cleveland, Ohio

Prepared for the

27th Joint Propulsion Conference

cosponsored by AIAA, SAE, ASME, and ASEE

Sacramento, California, June 24-27, 1991 


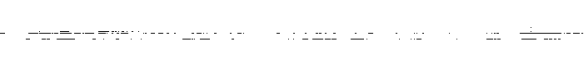

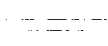




\title{
ION BEAM SPUTTERING IN ELECTRIC PROPULSION FACILITIES
}

\author{
James S. Sovey and Michael J. Patterson \\ National Aeronautical and Space Administration \\ Lewis Research Center \\ Cleveland, Ohio 44135
}

\begin{abstract}
Experiments were undertaken to determine sputter yields of potential ion beam target materials, to assess the impact of charge exchange on beam diagnostics in large facilities, and to examine material erosion and deposition after a $957 \mathrm{hr}$ test of a $5 \mathrm{~kW}$-class ion thruster. The xenon ion sputter yield of flexible graphite was lower than other graphite forms especially at high angles of incidence. Ion beam charge exchange effects were found to hamper beam probe current collection diagnostics even at pressures from 0.7 to $1.3 \mathrm{mPa}$. Estimates of the xenon ion beam envelope were made and predictions of the thickness of sputter deposited coatings in the facility were compared with measurements.
\end{abstract}

\section{Nomenclature}

$C(n, \ell)$ parameter defined by equation (4)

$\mathrm{dA}_{\mathrm{b}}, \mathrm{dA}_{\mathrm{t}}$ differential area, figure $2(\mathrm{~b}), \mathrm{m}^{2}$

$E$ ion energy, $e V$

$\mathrm{J}\left(\theta_{\ell}\right)$ ion current within limiting half-angle, equation (14), A

J(Total) total ion current, equation (14), A

$\mathrm{J}_{\mathrm{B}} \quad$ ion beam current, $A$

$\mathrm{J}_{B}(\mathrm{z}) \quad$ ion beam current at a distance $\mathrm{z}$ from thruster, A

$\mathrm{J}^{+}$beam current from singly charged ions, $\mathrm{A}$

$\mathrm{J++} \quad$ beam current from doubly charged ions, A

$\mathrm{j}(\mathrm{z}, \mathrm{r})$ current density at $(\mathrm{z}, \mathrm{r})$ and normal to target, $\mathrm{A} / \mathrm{m}^{2}$

$\mathrm{j}_{\mathrm{W}}(0,0)$ wall particle flux normal to thruster face, equivalent $\mathrm{A} / \mathrm{m}^{2}$

$\ell$

\begin{tabular}{|c|c|}
\hline $\mathbf{m}$ & mass of a given atom, $\mathrm{kg}$ \\
\hline $\mathbf{n}$ & shape function parameter, equation (3) \\
\hline$Q_{\mathbf{r}}$ & $\begin{array}{l}\text { resonance charge exchange cross-section for } \\
\text { xenon, } \mathrm{m}^{2}\end{array}$ \\
\hline $\mathbf{q}$ & ionic charge, $1.6 \times 10^{-19} \mathrm{C}$ \\
\hline $\mathbf{R}$ & vacuum facility radius, m \\
\hline $\mathbf{R}_{\mathbf{0}}$ & thruster radius, $m$ \\
\hline r & radial position, $\mathrm{m}$ \\
\hline$r_{b}$ & radial position, figure $2(\mathrm{~b}), \mathrm{m}$ \\
\hline$r_{s}$ & distance from $d A_{t}$ to $d A_{b}$, figure $2(b), m$ \\
\hline$r_{\ell}$ & limiting radial distance, equation (14), $\mathrm{m}$ \\
\hline $\mathbf{S}(\mathrm{E})$ & $\begin{array}{l}\text { sputter yield as a function of ion energy, } \\
\text { atoms/ion }\end{array}$ \\
\hline$S(\theta)$ & $\begin{array}{l}\text { sputter yield as a function of angle of incidence, } \\
\text { atoms/ion }\end{array}$ \\
\hline $\mathbf{t}_{b}\left(\mathbf{z}_{b}, \mathbf{r}_{b}\right)$ & $\begin{array}{l}\text { deposition rate as a function of distance } \\
\text { from target, } \mathrm{m} / \mathrm{s}\end{array}$ \\
\hline$t_{w}(z, r)$ & deposition rate from wall flux, $\mathrm{m} / \mathrm{s}$ \\
\hline $\mathrm{y}$ & $z / \mathbf{r}$ \\
\hline$y_{\ell}$ & limiting $z / r$, equation (15) \\
\hline $\mathbf{z}$ & axial distance from thruster, $m$ \\
\hline $\mathbf{z}_{\mathbf{b}}$ & axial distance from target, $\mathbf{z}_{\mathrm{T}^{-}} \mathrm{z}, \mathrm{m}$ \\
\hline $\mathbf{z}_{\mathbf{T}}$ & axial distance from thruster to target, $\mathrm{m}$ \\
\hline$\alpha$ & angle defined in figure $2(\mathrm{~b})$, radian \\
\hline$\Gamma$ & mass flux, $\mathrm{kg} / \mathrm{s} \mathrm{m}^{2}$ \\
\hline$\Gamma(z, r)$ & mass flux at $(z, r), \mathrm{kg} / \mathrm{s} \mathrm{m}^{2}$ \\
\hline$\Gamma_{b}\left(\mathbf{z}_{b}, \mathbf{r}_{b}\right)$ & mass flux from target at $\left(z_{b}, r_{b}\right), \mathrm{kg} / \mathrm{s} \mathrm{m}^{2}$ \\
\hline $\begin{array}{l}\Gamma_{w}(z, r) \\
\theta\end{array}$ & $\begin{array}{l}\text { mass flux from walls, } \mathrm{kg} / \mathrm{s} \mathrm{m}^{2} \\
\text { angle between target normal and incident ion beam } \\
\text { as shown in figure } 2(\mathrm{a}) \text {, radian }\end{array}$ \\
\hline$\theta_{r}$ & angle defined by equation (10), radian \\
\hline$\theta_{\ell}$ & limiting half-angle, equation (14), degree \\
\hline$\lambda$ & mean free path for charge exchange, $m$ \\
\hline & al density, $\mathrm{kg} / \mathrm{m}^{3}$ \\
\hline
\end{tabular}




\section{Introduction}

Ion propulsion applications for North/South stationkeeping, orbit transfer, and planetary propulsion generally have system lifetime requirements of 2000 to $10000 \mathrm{hr}$. Verification tests of thousands of hours are required in a vacuum environment that allows quantification of thruster life and reliability. Sputtered beam target and vacuum facility wall materials deposit on external thruster surfaces as well as internal thruster components. Deposition on the negative accelerator grid minimizes charge exchange ion erosion and yields more optimistic wear results than found in a true space environment (refs. 1 and 2). Spalled coatings on the ion extraction grid and/or from the thruster outer shroud may produce momentary shorts (high voltage faults) between the extraction grids. Flakes from sputtered facility material may also deposit inside the thruster discharge chamber. In order to minimize the sputtered backflux during extended tests, the ion beam target material should have a low sputter yield and to the extent possible, be configured so as to direct much of the efflux away from the vicinity of the thruster.

In the 1960 to 1980 timeframe, mercury was one of the primary propellants used for ion propulsion systems. Lifetests were generally conducted using frozen mercury targets so backsputtered metal from the vacuum facility was not of major concem (ref. 3). During the period 1987 to 1990, at least four extended tests using xenon propellant were conducted for periods from 570 to $4350 \mathrm{hr}$ (refs. 1, 2, 4 and 5). Operating conditions, basic dimensions of vacuum facilities, and type of beam target are shown in table 1. Sputtered backflux was reduced by either using graphite targets, a target with many box-like channels to provide a relatively large length/width ratio, or simply locating the target far from the thruster so the return flux to the thruster was relatively low.

Previous investigators have developed models of ion beam impingement of surfaces in the plume and also calculated the distribution of sputtered efflux (refs. 6 to 8), but there has been little work directed to experimentally validate these calculations. Some efflux data from target to thruster have been obtained using a quartz crystal microbalance, but without predictive analyses (ref. 2).

This paper will examine the beam target and witness plates that were used in a $957 \mathrm{hr}$ test of a $5 \mathrm{~kW}$-class xenon ion thruster to determine material erosion and deposition rates. Since beam ion charge exchange had a major impact on ion current density profile measurements, profiles were derived from beam target mass loss data. The ion beam spread was estimated, and calculated deposition from the target and facility walls was compared with experiment. The sputter yields of three forms of graphite, which are potential beam target materials, were determined at a beam energy of $1410 \mathrm{eV}$ and various angles of incidence. Results were compared with a small set of carbon sputter yield data found in the literature.

\section{Apparatus and Procedure}

All of the erosion and deposition data were obtained after a lifetest of a $5.5 \mathrm{~kW}$ xenon ion thruster. The thruster, test facility, beam probes, and erosion and deposition diagnostics are described.

\section{Thruster}

The laboratory model xenon thruster was comprised of a ring-cusp discharge chamber magnetic circuit, a main discharge hollow cathode, and a hollow cathode neutralizer (ref. 1). The two-grid ion optics system had an effective beam diameter of $0.282 \mathrm{~m}$. The grids were dished to a depth of $2.3 \mathrm{~cm}$, and grid thicknesses were $0.36 \mathrm{~mm}$ with a nominal spacing of $0.76 \mathrm{~mm}$. Positive and negative grid hole diameters were 1.9 and $1.1 \mathrm{~mm}$, respectively. The open area fraction was 0.67 for the positive grid and 0.24 for the negative grid. The positive grid hole pattern was sized down or "compensated" by about 0.35 percent to steer the beamlets along the thruster axis (ref. 9). At an input power of $5.5 \mathrm{~kW}$, the nominal operating conditions were a beam voltage of $1530 \mathrm{~V}$, a beam current of $3.19 \mathrm{~A}$, and a total xenon flow rate of 3.66 equivalent amperes $\left(5.3 \times 10^{-6} \mathrm{~kg} / \mathrm{s}\right)$. Overall performance was about $3800 \mathrm{~s}$ specific impulse with a thrust efficiency of 0.68 . Surfaces in the test facility were exposed to $957 \mathrm{hr}$ of thruster operation at the $3.19 \mathrm{~A}$ beam current.

\section{Test Facility}

The vacuum test facility, figure 1 , was $4.5 \mathrm{~m}$ diameter by $19.2 \mathrm{~m}$ long. Twenty $0.8 \mathrm{~m}$ diameter oil diffusion pumps provided a base pressure of $6.7 \times 10^{-5} \mathrm{~Pa}$. The operating pressure was $1.7 \times 10^{-3} \mathrm{~Pa}$ at the $3.19 \mathrm{~A}$ xenon beam current condition.

To minimize sputtered efflux a graphite target was mounted on an existing aluminum louvre system located $9.37 \mathrm{~m}$ from the thruster ion optics. A $0.95 \mathrm{~m}$ diameter, $2.5 \mathrm{~cm}$ thick isotropic graphite disc was located at the center of the target. The rest of the target was covered with $0.25 \mathrm{~mm}$ thick flexible graphite to a diameter of about $4.4 \mathrm{~m}$. After the extended test, $5.2 \mathrm{~cm}^{2}$ samples of the flexible graphite were removed from the target for thickness and mass measurements. Samples were obtained from 0.5 to $2 \mathrm{~m}$ along four radii separated azimuthally by $90^{\circ}$. Many glass substrates were installed in the facility to measure the thickness and chemistry of films produced from sputtered efflux.

\section{Beam Probes}

After the extended test, three $5.05 \mathrm{~cm}$ diameter molybdenum planar probes (ref. 10) were mounted on the target. The radial positions of the probes were on centerline, 1.14 , and $1.75 \mathrm{~m}$. Probes were biased at $-20 \mathrm{~V}$ to suppress electrons. Secondary 
electron emission effects caused by impingement of xenon ions on molybdenum were expected to be less than 5 percent (ref. 11). However, the planar probes detected both fast beam ions and slow charge exchange ions. The probe measurements provided some insight into the extent of charge exchange interactions.

\section{Sputter Yield Measurements}

Sputter yield measurements were made using a xenon ion source masked to a $15 \mathrm{~cm}$ beam diameter. Ion source conditions were set so that $1410 \mathrm{eV}$ xenon ions at an ion current density of $10 \mathrm{~A} / \mathrm{m}^{2}$ bombarded a target when it was normal to the ion beam. The current density to the target was reduced by the cosine of the angle of incidence as the target was rotated. Since the sputter yield measurements were made prior to the $957 \mathrm{hr}$ test, $1410 \mathrm{eV}$ was simply an estimate of the life test thruster beam energy. The target center was located $4.8 \mathrm{~cm}$ downstream of the ion source. Current densities were obtained using a $0.28 \mathrm{~cm}^{2}$ molybdenum planar probe biased at $-30 \mathrm{~V}$ to suppress electron collection.

In subsequent graphite target sputter erosion calculations it was assumed that the sputter yield was independent of ion current density from about 0.1 to $10 \mathrm{~A} / \mathrm{m}^{2}$. Studying the effects of absorbed gases on the graphite target sputter yield, especially at low current densities, was beyond the scope of this work. Absorbed gases on the target would tend to decrease the target sputter erosion (ref. 11). During the extended thruster test, the partial pressure due to background gases such as nitrogen, oxygen, and water was only $6.7 \times 10^{-4} \mathrm{~Pa}$. During thruster operation the facility pressure was $1.7 \times 10^{-3} \mathrm{~Pa}$ and was due primarily to xenon.

Target materials were isotropic graphite, pyrolytic graphite, and flexible graphite with specific gravities of 1.8, 2.0, and 1.1 , respectively. The target specimens were shaped so four "pie sections" would comprise a $3.4 \mathrm{~cm}$ diameter disc. The four specimens, which comprised each type of graphite and a redundant isotropic graphite sample, were mounted in an isotropic graphite fixture so their surfaces were flush with the fixture surface. The target assembly was rotated about its axis at $1 \mathrm{rev} / \mathrm{min}$ to insure uniform sputtering. The ion current density variation over the $3.4 \mathrm{~cm}$ diameter was less than 3 percent at normal incidence. A separate test with a molybdenum target was conducted for comparison at normal incidence. The highest vacuum facility pressure during the sputtering process was about $1 \times 10^{-2} \mathrm{~Pa}$, which is sufficiently low so charge exchange effects would not impact current density measurements at a distance of $5 \mathrm{~cm}$ from the ion source.

Ion sputtering was performed for 2.5 to $4.5 \mathrm{hr}$ to insure specimen mass losses in the 1.0 to $3.0 \mathrm{mg}$ range. The ion sputter yield calculated from the target mass loss rate relation is:

$$
\Gamma=j(\mathbf{z}, \mathbf{r}) S(\theta) m / q
$$

\section{Thin Film Measurements}

The thickness of films deposited on glass substrates was measured by either using a profilometer or a scanning electron microscope. Film thicknesses ranged from 0.5 to $2.2 \mu \mathrm{m}$. Film chemistry provided the relative abundance of carbon versus stainless steel products which would help validate ion beam envelope assessments. Batches of spalled flakes from various locations were spectrochemically analyzed to quantitatively determine the constituents such as iron, nickel, and chromium. The carbon content of the flakes was determined by converting the carbon to carbon dioxide for gas analysis.

\section{Analytical Procedure}

\section{Ion Current Density Profiles}

Since charge exchange collisions were expected to impact the far-field planar probe ion current density profile, the profile was obtained from target mass loss data. The curve-fitted target mass loss data were used to calculate sputtered efflux from the target. The ion current density, calculated from the mass loss data, was used to estimate the backflux from the facility walls and also to define the beam envelope. The mass flux leaving the target can be approximated as:

$$
\Gamma\left(\mathrm{z}_{\mathrm{T}}, \mathrm{r}\right)=j\left(\mathrm{z}_{\mathrm{T}}, \mathrm{r}\right) S(\theta) m / q
$$

assuming only singly charged xenon ions. The variable $j\left(\mathrm{z}_{T}, \mathrm{r}\right)$, was calculated from the measured values of $\Gamma\left(z_{T}, r\right)$ and $S(\theta)$. At the extremity of the target, the angle is only $13.6^{\circ}$ so the the sputter yield was nearly constant across the target. Iterative methods were used to curve-fit the data using the far-field extended source current density relations developed in reference 6 . The current density relation describes a profile with a flat central core and an exponential dropoff with increasing distance from the thruster centerline. This equation has been shown to adequately describe far-field current density profiles obtained experimentally from a variety of ion thrusters (ref. 6). The geometry is shown in figure 2(a).

$$
\begin{gathered}
\mathrm{j}\left(\mathrm{z}_{\mathrm{T}}, \mathrm{r}\right)=\mathrm{C}(\mathrm{n}, \ell) \frac{\mathrm{J}_{\mathrm{B}}}{\pi \mathrm{z}^{2}} \exp -\left[\ell\left(1-\frac{\mathrm{z}_{\mathrm{T}}}{\sqrt{\mathrm{z}_{\mathrm{T}}^{2}+\mathrm{r}^{2}}}\right)\right]^{\mathrm{n}} \\
\mathrm{C}(\mathrm{n}, \ell)=\frac{1}{2 \int_{0}^{\infty} \exp -\left[\ell\left(1-\frac{1}{\sqrt{1+y^{2}}}\right)\right]^{n} y d y}
\end{gathered}
$$


The value of $\mathrm{C}(\mathrm{n}, \ell)$ was obtained by using equation (3) when $r=0$. The values of $n$ and $\ell$ were obtained by iteration to best fit the data. The $n$ and $\ell$ values also satisfied equation (4).

\section{Carbon Efflux from the Target}

Xenon ions impinge on the graphite target producing a sputtered mass flux toward the thruster and other facility surfaces. A mathematical expression is sought to define the profile of deposited material from the target. The target and deposition plane are parallel. The geometry is shown in figure 2(b). With a cosine law of emission used to describe the mass flux issuing from a disc source (ref. 8), the deposited mass flux can generally be described as:

$$
\Gamma_{b}\left(\mathrm{z}_{b}, \mathrm{r}_{b}\right)=\iint_{r} \Gamma\left(\mathrm{z}_{\mathrm{T}}, \mathrm{r}\right) \frac{\mathrm{z}_{b}^{2} d \alpha r d r}{\pi r_{s}^{4}}
$$

After substituting for $r_{\mathrm{s}}$ and integrating $\alpha$ from 0 to $2 \pi$ :

$$
\Gamma_{b}\left(\mathrm{z}_{b}, \mathrm{r}_{b}\right)=2 \int_{0}^{R_{\mathrm{T}}} \frac{\Gamma\left(\mathrm{z}_{\mathrm{T}}, \mathrm{r}\right) \mathrm{z}_{b}^{2}\left(\mathrm{z}_{b}^{2}+\mathrm{r}_{b}^{2}+\mathrm{r}^{2}\right) r d r}{\left[\left(\mathrm{z}_{b}^{2}-\mathrm{r}_{b}^{2}+\mathrm{r}^{2}\right)^{2}+\left(2 \mathrm{r}_{b} \mathrm{z}_{b}\right)^{2}\right]^{\frac{3}{2}}}
$$

This integrated expression yields the sputtered mass flux from an extended circular disc source. The variable $z_{b}$ is simply $z_{T}-z$. The film deposition rate is related to the sputtered mass flux by:

$$
i_{b}\left(\mathrm{z}_{b}, \mathrm{r}_{b}\right)=\frac{\Gamma_{b}\left(\mathrm{z}_{b}, \mathrm{r}_{b}\right)}{\rho}
$$

\section{Wall Backflux to Thruster}

Assuming a cosine distribution of sputtered efflux off the tank walls, the wall backflux to the thruster face can be expressed as (ref. 6):

$$
j_{w}(0,0)=2 R^{2} \int_{0}^{\mathrm{Z}_{\mathrm{\tau}}} \frac{j(\mathrm{z}, \mathrm{R}) \tan \theta S\left(\frac{\pi}{2}-\theta\right) z d z}{\left(\mathrm{z}^{2}+R^{2}\right)^{2}}
$$

where the high energy ion or atom arrival rate on the cylindrical wall is related to the arrival rate at the target periphery by:

$$
[j(\mathbf{z}, \mathbf{R})]_{\text {Tankwall }}=[j(\mathbf{z}, \mathbf{R})]_{\text {Traget }} \tan \theta
$$

The basic parameters are shown in figure 2(a). Here the back flux is expressed in equivalent amperes $/ \mathrm{m}^{2}$. Using the farfield expression for the ion current density (eq. (3)), the wall flux to the thruster face is:

$$
\mathrm{j}_{w}(0,0)=\frac{-2 \mathrm{~J}_{B} \mathrm{C}(\mathrm{n}, \ell)}{\pi \mathrm{R}^{2}} \int_{\frac{\pi}{2}}^{\theta_{\mathrm{r}}} \mathrm{S}\left(\frac{\pi}{2}-\theta\right) \exp -[\ell(1-\cos \theta)]^{\bar{D}} \frac{\sin ^{4} \theta}{\cos ^{2} \theta} \mathrm{d} \theta
$$

where

$$
\theta_{r}=\arctan \frac{R}{z_{\tau}}
$$

Expressed in $\mathrm{kg} / \mathrm{m}^{2} \mathrm{~s}$, the retum flux is:

$$
\Gamma_{w}(0,0)=j_{w}(0,0) \mathrm{m} / \mathrm{q}
$$

and the corresponding deposition rate is:

$$
i_{w}(0,0)=\Gamma_{w}(0,0) / \rho
$$

When steel was considered in the calculations, iron values were used for the atomic mass and density. This is a reasonable approximation since the composition of 304 stainless steel, for example, is about 19 percent $\mathrm{Cr}, 10$ percent $\mathrm{Ni}$, and 71 percent $\mathrm{Fe}$. The atomic masses of chromium, nickel and iron are 52,59 , and 56 , respectively.

\section{Ion Beam Envelope}

As developed in reference 6, the fraction of total ion beam current enclosed within a given half-angle $\theta_{\ell}$ about the beam centerline is:

$$
\frac{\mathrm{J}\left(\theta_{\ell}\right)}{\mathrm{J}(\text { Total })}=\frac{2 \pi \int_{0}^{\mathrm{r}_{\mathrm{l}}} \mathrm{j}(\mathrm{z}, \mathrm{r}) \mathrm{rdr}}{2 \pi \int_{0}^{\infty} \mathrm{j}(\mathrm{z}, \mathrm{r}) \mathrm{rdr}}
$$

and

$$
\frac{\mathrm{J}\left(\theta_{\ell}\right)}{\mathrm{J}(\text { Total })}=2 \mathrm{C}(\mathrm{n}, \ell) \int_{0}^{\mathrm{y}_{\ell}} \exp -\left[\ell\left(1-\frac{1}{\sqrt{1+\mathrm{y}^{2}}}\right)\right]^{\mathrm{n}} \mathrm{ydy}
$$

Equation (15) is valid for $Z>8 R_{o}$ and can be used to determine which portions of the tank wall (or target) significantly contribute to the sputtered retum flux.

\section{Results and Discussion}

Results of graphite sputter yield measurements will be discussed followed by experimental examinations of ion current density and sputter erosion profiles. The sputtered efflux from a beam target and facility walls was calculated and 
results were compared with deposition on substrates near the thruster and on facility walls.

\section{Sputter Yields}

In order to characterize the mass flux distribution emanating from an ion sputtered surface, accurate sputter yicld data are needed for ion impingement angles from 0 to about $80^{\circ}$ from the target normal. Xenon sputter yields for isotropic graphite, pyrolytic graphite, and flexible graphite were obtained at $1410 \mathrm{eV}$ for angles of incidence of $0^{\circ}, 45^{\circ}$, and $70^{\circ}$. At normal incidence, the sputter yield for flexible graphite was 0.48 which was lower than isotropic and pyrolytic graphite which had values of 0.61 to 0.49 , respectively. These data compare well with other published results for carbon as shown in figure 3 (refs. 11 to 13). Since there is very little sputter yield data for xenon on carbon, the sputter yield of molybdenum was measured at $1410 \mathrm{eV}$ to provide additional confidence in the measurement. The molybdenum sputter yield is about 3.7 times that of the graphite forms and compares very well with previously cited values as shown in figure 3 (refs. 12, 14 and 15)

The sensitivity of graphite sputter yield to angle of incidence is shown in figure 4 . In all cases, the flexible graphite has a lower sputter yield than isotropic and pyrolytic graphite. As the angle of incidence is varied from 0 to $70^{\circ}$, the flexible graphite sputter yield doubled while the isotropic and pyrolytic graphite sputter yiclds approximately tripled. The specific gravities of pyrolytic, isotropic, and flexible graphite are 2.0 , 1.8 , and 1.1, respectively. Because the flexible graphite has such a low density, the range of energetic particles in the target would be larger so that the transmission of energy back to the surface where sputtering occurs would be less efficient (ref. 11). It is well known that surfaces of most types of graphite are readily textured by ion impingement. The micrometer-sized needles or cones produced by the texturing process will likely impact the sputter yields (ref. 16). Assuming $S(\theta)$ monotonically increases from 45 to $70^{\circ}$, and there is no inflection point in the sputter yield curve at least up to $70^{\circ}$, the flexible graphite sputter yield data can be curve-fitted over an angle of incidence range from 0 to $70^{\circ}$ :

$$
S(\theta)=0.48+0.0283 \theta+0.305 \theta^{2}
$$

where $\theta$ is in radians. Equation (16) is valid for $<1.22$ radians. More detailed sputter yield measurements are still needed to carefully define the curve between angles of incidence from 45 to $80^{\circ}$.

The xenon ion sputtering of the steel facility walls was approximated by using the iron sputter yield of 2.18 for normal incidence at $1410 \mathrm{eV}$. This value was obtained by interpolation using the data of references 12 and 17. The angular dependence of the iron sputter yield was approximated using the shape function of mercury ions on iron at $800 \mathrm{eV}$ (ref. 18). The estimate of the sputter yield of xenon on iron is shown in figure 5. After normalization for xenon at normal incidence at $1410 \mathrm{eV}$, the sputter yield is approximated by:

$$
S(\theta)=2.18+6.43 \theta-39.6 \theta^{2}+88.2 \theta^{3}-44.8 \theta^{4}
$$

where $\theta$ is in radians. The value of $S(\theta)$ for xenon on iron at $1410 \mathrm{eV}$ using a shape function from mercury ion data at $800 \mathrm{eV}$ may be overestimated by 20 to 50 percent based on the sensitivities of $S(\theta) / S(0)$ as copper was sputtered by various ions over a range of energy from 550 to $2050 \mathrm{eV}$ (ref. 19). Using the copper example, $S(\theta) / S(0)$ generally increased with increased ion mass at fixed energy and decreased with increased ion energy at fixed ion mass.

In the following analyses it was assumed that the sputter yield was the same for ionic or atomic beams incident on a target. This assumption has been verified for ionic and atomic argon sputtering of copper and nickel (ref. 20).

\section{Mass Flux and Current Density Profiles}

During the course of this study it was found that beam probes located many meters downstream of the thruster would yield inaccurate ion current density profiles at a facility pressure of $1.7 \times 10^{-3} \mathrm{~Pa}$ because a high fraction of beam ions encountered charge exchange. As an ion beam passes through a background gas, its ion current decreases as (ref. 21):

$$
\frac{J_{\mathrm{B}}(\mathrm{z})}{J_{\mathrm{B}}}=\exp \left(-\mathrm{n}_{0} \mathrm{Q}_{\mathrm{r}} \mathrm{z}\right)
$$

where the ion mean free path for charge exchange is given by:

$$
\lambda=\frac{1}{\mathrm{n}_{0} \mathrm{Q}_{\mathrm{r}}}
$$

For the lifetest conditions examined here, the number density was calculated from the facility pressure and the temperature of the background gas which was assumed to be at the facility wall temperature. Cross-section data were obtained from reference 22 . The extended test facility pressure of $1.7 \times 10^{-3} \mathrm{~Pa}$ and a xenon ion beam energy of $1530 \mathrm{eV}$ yielded a mean free path for charge exchange of $7.8 \mathrm{~m}$. Figure 6 , curve 2 , shows that at the beam target approximately 70 percent of the beam ions had experienced charge exchange. If the cross-sections of reference 22 are reasonably accurate, nearly 6 percent of the ion beam was comprised of fast neutrals at a distance of only $0.5 \mathrm{~m}$ from the thruster. At better vacuum facility pressures below about $6.7 \times 10^{-4} \mathrm{~Pa}$, beam probe data would not be seriously impacted by charge exchange phenomena at distances up to $25 \mathrm{~cm}$ from the thruster.

Since far-field beam probe data could not be relied upon, beam profile and beam envelope information were extracted 
from target mass loss data. The target mass loss rate, obtained by weighing specimens of the flexible graphite, is shown versus target radius in figure 7 . By integrating the local mass flux measurements, the total mass lost from the $4.52 \mathrm{~m}$ diameter target during the $957 \mathrm{hr}$ of operation was approximately $0.55 \mathrm{~kg}$. This results in about $36 \mathrm{~g}$ of carbon sputtered from the target per square meter per $1000 \mathrm{hr}$. The experimental measurement of the mass loss distribution exhibited data scatter as much as \pm 27 percent. The flexible graphite had density variations in the 5 to 10 percent range. During the course of the test the flexible graphite had many surface undulations such that many surfaces did not provide normal incidence; this factor may be the major cause of the data scatter. Target erosion depth calculated from the mass loss and density was generally within 10 percent of the measured value. Nominal target erosion after $3050 \mathrm{~A}-\mathrm{hr}$ of xenon impingement at $1530 \mathrm{eV}$ was about $50 \mu \mathrm{m}$ at a $0.5 \mathrm{~m}$ radius to $30 \mu \mathrm{m}$ at $1.9 \mathrm{~m}$ radius.

Figure 8 shows ion current density data derived from the mass flux data of figure 7 using equations (2) and (3). Since detailed charge state data for the thruster were not taken, singly charged ions were assumed. The ratio of doubly to singly charged ions at the operating condition of table I would be as high as 0.2 to 0.3 at the thruster centerline, and lower ratios would be expected at larger radii (ref. 23). The effective sputter yield can be written as:

$$
\frac{S(\mathrm{E})+0.5 \frac{\mathrm{J}++}{\mathrm{J}+} S(2 \mathrm{E})}{1+\frac{J++}{J+}} \approx S(\mathrm{E}) \frac{1+0.5 \frac{J++}{J+}}{1+\frac{J++}{J+}}
$$

since the slope of the xenon on carbon sputter yield (fig. 3) is very shallow from 1400 to $3000 \mathrm{eV}$. Because of the effect of doubly charged ions, the calculated centerline ion current density might be 8 to 12 percent higher than that predicted using only singly ionized species. The uncertainty in calculated current density at other radii would be smaller because the ratio $\mathrm{J}++/ \mathrm{J}+$ is smaller.

The solid curve in figure 8 is a curve fit of the ion current density profile using equation (3). The resulting curve fit parameters $n=2,1=45$ imply a rather collimated beam profile (ref. 6). The profile can be expressed as:

$$
j(9.37, \mathrm{r})=0.29 \exp -\left[45\left(1-\frac{9.4}{\sqrt{9.4^{2}+\mathrm{r}^{2}}}\right)\right]^{2}
$$

Also shown in the figure are the planar probe data at the target location. The ratio of ion current density derived from target mass loss data to measured values varies from about 2.1 to 2.8 indicating significant ion beam charge exchange. These ratios would have been larger if Faraday cup probes with positively biased collectors had been used since the planar probes also collect a small amount of low energy charge exchange ions.

In order to check the derivation of ion current density profiles from the mass flux profiles, ion erosion of two steel washers was measured. Table II shows the measured erosion depth of a steel washer, part of which was masked by a bolthead. The measured erosion depth on the two washers was about $110 \mu \mathrm{m}$ which resulted in an crosion rate of $2.3 \times 10^{-7} \mathrm{~kg} / \mathrm{m}^{2} \mathrm{~s}$. The calculated ion erosion depth using the ion current density of figure 8 was $160 \mu \mathrm{m}$ which was 45 percent higher than the measured value. The sputter yield of iron was used to calculate the erosion of the steel material. Based on atomic mass, density, and sputter yield ratios, the erosion depth ratio of iron to flexible graphite would be expected to be 3 rather than the measured value of 2 . The erosion depth ratio is independent of the local current density. The disparity in measured versus calculated ion erosion using steel might have been due to local deposition of sputtered material from the bolthead.

Figure 9 shows ion beam envelope information based on the curve fit parameters $n=2, \ell=45$, and equation (15). Shown on the figure is the target edge which defines a $13.6^{\circ}$ halfangle with respect to the thruster centerline. Approximately 94 percent of the ion beam impinged on the target. About 99 percent of the beam was enclosed within a $15^{\circ}$ half-angle which implies nearly all ion impingement is on the target or on facility walls within one meter from the target. Thus, a small amount of facility wall material was sputtered on the target and adjacent walls producing multicomponent coatings in the facility. The beam envelope results compare favorably with data reported in reference 24 where similar ion optics were tested. In this case about 95 percent of the beam was contained within a $14^{\circ}$ half-angle.

\section{Deposition from Target and Walls}

The deposition of carbon from the target onto the thruster face or facility surfaces was measured after the $957 \mathrm{hr}$ test. The deposition was also calculated using the cosine law of emission developed in reference 8. About 94 percent of the ion beam current was estimated to impinge on the graphite target located $9.37 \mathrm{~m}$ from the thruster. Using equation (6) and (7) the carbon mass flux from the target and film thickness on the thruster face can be calculated after having determined the sputtered mass loss distribution from the target using equation (2). The film thickness on the thruster face derived from target material was calculated to be $2 \mu \mathrm{m}$. Using equations (12) and (13) the deposition of material from the facility walls to the thruster face was calculated. For all stainless steel or all carbon coated walls the resulting film thicknesses were 0.3 and $0.1 \mu \mathrm{m}$, respectively. Thruster ground screen material that was masked and exposed to the efflux was measured with a micrometer accurate to $5 \mu \mathrm{m}$. A film thickness greater than $5 \mu \mathrm{m}$ was not detected. This crude 
measurement is not inconsistent with calculated film thicknesses which were estimated to be in the 2.1 to $2.3 \mu \mathrm{m}$ range.

Better measurements of film properties were obtained from a coated glass slide located on the facility bulkhead $0.8 \mathrm{~m}$ downstream and $1.5 \mathrm{~m}$ radially from the thruster. The film thickness was measured by a profilometer to be $2.2 \mu \mathrm{m}$. The calculated film thickness from the graphite target after $957 \mathrm{hr}$ of thruster operation was $2.2 \mu \mathrm{m}$, equation (7). The approximate values of film thickness from stainless steel or graphite walls were 0.4 and $0.1 \mu \mathrm{m}$, respectively based on a calculation of $j_{w}(0.8 \mathrm{~m}, 0)$. The overall film thickness was calculated to be in the range of 2.3 to $2.6 \mu \mathrm{m}$ which exceeds the witness plate measurement by 5 to 18 percent depending on the composition of coatings on the facility walls. If all the wall flux were stainless steel products, the carbon mass fraction of the film could be as low as 0.45 .

The facility walls serve as a second beam target so it is necessary to know the composition of films deposited on the walls or whether the stainless steel walls are free of coatings. Figure 10 shows the chemistry of spalled films from facility walls versus axial distance along the walls. At a location $0.8 \mathrm{~m}$ downstream of the thruster, along the facility wall, the mass ratio and atomic number density ratio of carbon to stainless steel products were 0.38 and 1.8 , respectively. At locations of 1.7 and $3.8 \mathrm{~m}$ downstream of the thruster the mass of carbon in the films was less than 1.5 percent of the mass of the stainless steel products, iron, nickel, and chromium. In fact, using tape to peel films from the tank walls revealed that the wall region from $5 \mathrm{~m}>\mathrm{z}>2.8 \mathrm{~m}$ was ion cleaned implying erosion dominated deposition. This erosion was likely produced by wide angle, low current density ions which were not predicted by the data of figure 8 . More detailed measurements are needed to quantify the amount of wide angle ions. Other models such as the "parabolic core with exponential wings" might better describe the wide angle distribution, (ref. 10).

Figure 10 shows that most wall surfaces of the facility were deposited with films having various concentrations of $\mathrm{C}, \mathrm{Fe}$, $\mathrm{Cr}$, and $\mathrm{Ni}$. Coatings on the wall one meter from the target had carbon to stainless steel product mass and number density ratios of 1.1 and 5.2, respectively. Mass concentrations of iron, chromium, and nickel in the films $1 \mathrm{~m}$ from the target were as high as 29,6 , and 9 percent, respectively. Carbon comprised 49 percent of the film by mass. From the beam envelope results about 6 percent of the ion beam intercepted the facility wall near the target. Erosion of wall material or films on the wall would likely compete strongly with wide angle target deposition in this region.

\section{Concluding Remarks}

Experiments were undertaken to determine sputter yields of potential beam target materials, to assess the impact of charge exchange on beam diagnostics in large facilities, and to examine material erosion and deposition after a $957 \mathrm{hr}$ test of a $5 \mathrm{~kW}$-class xenon ion thruster. The xenon ion sputter yields of flexible graphite, pyrolytic graphite, and isotropic graphite were measured at ion incidence angles of 0,45 , and $70^{\circ}$. At normal incidence the sputter yields of all carbon forms were about the same (0.48 to 0.61$)$. However, at an angle of incidence of $70^{\circ}$ the flexible graphite sputter yield doubled from the normal incidence value while the isotropic graphite yield tripled. The low density and surface structures of flexible graphite may have promoted some deposition of sputtered carbon at the target surface.

Examination of the extended test conditions of the $5 \mathrm{~kW}$ ion thruster indicated that a high fraction of beam ions encountered charge exchange at a facility pressure of $1.7 \times 10^{-3} \mathrm{~Pa}$ and a beam energy of $1530 \mathrm{eV}$. The mean free path for xenon charge exchange at these conditions was about $7.8 \mathrm{~m}$ while the distance from the thruster to the target was $9.37 \mathrm{~m}$. At the target about 70 percent of the beam was estimated to be fast neutral xenon. Under these conditions Faraday cup and biased planar probes would be of little value for ion current density measurements. Even at $0.5 \mathrm{~m}$ from the thruster, 6 percent of the ion beam was estimated to have undergone charge exchange. Since the xenon charge transfer cross-section is rather high, care must be taken in the interpretation of far-field ion current density probe data even at facility pressures as low as $7 \times 10^{-4} \mathrm{~Pa}$.

Over the course of the extended test there was $3050 \mathrm{~A}-\mathrm{hr}$ of xenon impingement on the target at $1530 \mathrm{eV}$ which resulted in about $36 \mathrm{~g}$ of flexible graphite target material lost per square meter per $1000 \mathrm{hr}$. The erosion depth was 30 to $50 \mu \mathrm{m}$ over much of the target. The target mass loss distribution was curve-fitted to estimate the beam envelope. At the target distance of $9.37 \mathrm{~m}$, about 94 percent of the beam impinged on the target and 99 percent of the beam was enclosed in a $15^{\circ}$ half-angle. Using the cosine law of emission for the target mass loss distribution and wall flux calculations, the thickness of films in the vicinity of the thruster were predicted within 5 to 18 percent of measured values. Major uncertainties in the calculations were due to the current density estimates and the composition of coatings on the facility walls. Some wall erosion was produced by wide angle, low current density ions. This erosion was not predicted by the curve-fitting of the target mass loss distribution. More detailed measurements are needed to quantify the percentage of wide angle ions since they may impact spacecraft integration.

\section{Acknowledgment}

The efforts of Frances Archer of NASA Lewis Research Center in the spectrochemical analyses of spalled coatings are gratefully acknowledged. 


\section{References}

1. Patterson, M. J.; and Verhey, T. R.: 5-kW Xenon Ion Thruster Lifetest. AIAA Paper 90-2543, July 1990. (Also, NASA TM-103191.)

2. Kitamura, S.; Miyazaki, K.; and Hayakawa, Y.: 1000 Hour Test of a $14 \mathrm{~cm}$ Diameter Ring-Cusp Xenon Ion Thruster. AIAA Paper 90-2542, July 1990 .

3. Colletl, C.: Thruster Endurance Test. NASA CR-135011, 1976.

4. Beattie, J.R.; and Matossian, J.N.: Xenon Ion Propulsion for Stationkeeping and Orbit Raising. DGLR/AIAA/JSASS Paper IEPC-88-052, Oct. 1988.

5. Rawlin, V. K.: Internal Erosion Rates of a 10-kW Xenon Ion Thruster, ALAA Paper 88-2912, July 1988. (Also, NASA TM-100954).

6. Reynolds, T.W.: Mathematical Representation of Current Density Profiles from Ion Thrusters. AIAA Paper 71-693, June 1971. (Also, NASA TN D-6334).

7. Reynolds, T.W.; and Richley, E.A.: Contamination of Spacecraft Surfaces Downstream of a Kaufman Thruster. NASA TN D-7038, 1971.

8. Maissel, L.I.; and Glang, R.: Handbook of Thin Film Technology. McGraw-Hill, 1970.

9. King, H.J.: Low Voltage $30-\mathrm{cm}$ Ion Thruster Development. NASA CR-134731, 1974.

10. Komatsu, G.K.; and Stellen, J.M.: Beam Efflux Measurements. NASA CR-135038, 1976.

11. Caner, G.; and Colligon, J.S.: Ion Bombardment of Solids. Elsevier, 1968.

12. Rosenberg, D.; and Wehner, G.K.: Sputtering Yields for Low Energy $\mathrm{He}^{+}, \mathrm{Kr}^{+}$, and $\mathrm{Xe}+$ Ion Bombardment. J. Appl. Phys., vol. 33, no. 5, May 1962, pp. 1842-1845.

13. Hechtl, E; and Bohdansky, J.: Sputtering Behavior of Graphite and Molybdenum at Low Bombarding Ejergies. J. Nucl. Mater., vol. 123, 1984, pp. 1431-1436.
14. Koshkin, V.K.; Rysov, J.A.; Shkarban, I.I.; and Goumin, B.M.: On the Cathode Sputtering of Polycrystals. Proceedings of the 9th Intemational Conference on Phenomena of Ionized Gases, G. Musa, ed., Editura Academiei Republici: Socialiste Romania, Bucharest, 1969 , p. 92.

15. Weijsenfeld, C.H.: Yield, Energy, and Angular Distribution of Sputtered Atoms. Phillips Research Report, Suppl. No. 2, 1967.

16. Wintucky, E.G.; Curren, A.N.; and Sovey, J.S.: Electron Reflection and Secondary Emission Characteristics of Sputter-Textured Pyrolytic Graphite Surfaces. Thin Solid Films, vol. 84, no. 2, 1981, pp. $161-169$.

17. Andersen, H.H.; and Bay, H.L.: Sputtering Yield Measurements. Sputtering by Particle Bombardment, R. Behrisch, ed., Springer-Verlag, 1981, pp. 145-218.

18. Wehner, G.: Influence of the Angle of Incidence on Sputtering Yields. J. Appl. Phys., vol. 30, no. 11, Nov. 1959, pp. 1762-1765.

19. Oechsner, H.: Sputtering of Polycrystalline Metal Surfaces at Oblique Ion Bombardment in the $1 \mathrm{keV}$ Range. Z. Physik, vol. 261, 1973, pp. 37-58.

20. Barskaya, A.Y., et al.: Sputtering of Various Materials by Ions and Atoms. Soviet Phys. Tech. Phys., vol. 32, no. 6, 1987, pp. 724-725.

21. Kaufman, H.R.: Industrial Ion Source Technology. NASA CR-135353, 1977.

22. Rapp, D.; and Francis, W.E.: Charge Exchange between Gaseous Ions and Atoms. J. Chem. Phys., vol. 37, no. 11, Dec. 1, 1962, pp. 2631-2645

23. Beattie, J.R.: Hughes Research Laboratories, Private Communication.

24. Beattie, J.R.; Matossian, J.N.; and Robson, R.R.: Status of Xenon Ion Propulsion Technology. J. Propulsion Power, vol. 6, no. 2, Mar.Apr. 1990, pp. 145-150. 
TABLE I.-LIFETEST PARAMETERS

\begin{tabular}{|c|c|c|c|c|}
\hline Reference & Ref. 4 & Ref. 5 & Ref. 2 & Ref. 1 \\
\hline \multicolumn{5}{|l|}{ Parameter } \\
\hline Thruster diameter, $\mathrm{cm}$ & 25 & 28.2 & 14 & 28.2 \\
\hline Propellant & $\mathrm{Xe}$ & $\mathrm{Xe}$ & $\mathrm{Xe}$ & $\mathbf{X e}$ \\
\hline Input power, kW & 1.34 & 10 & $0.56^{\mathrm{a}}$ & 5.51 \\
\hline Specific impulse, s & 2800 & 4020 & 3030 & 3840 \\
\hline Thrust, $\mathbf{N}$ & 0.064 & 0.33 & 0.023 & 0.20 \\
\hline Overall efficiency & 0.65 & 0.65 & $0.61^{8}$ & 0.68 \\
\hline Beam voltage, $V$ & 750 & 1810 & 1000 & 1530 \\
\hline Beam current, $A$ & 1.45 & 5.0 & 0.46 & 3.19 \\
\hline Beam power, $\mathrm{kW}$ & 1.1 & 9.0 & 0.46 & 4.90 \\
\hline Dicharge voltage, $\mathrm{V}$ & 28 & 28 & 33-39 & 26.9 \\
\hline Emission current, A & 6.3 & 31 & 3 & 18.8 \\
\hline Estimated $\mathrm{J}++/ \mathrm{J}+$ (av.) & $-\cdots$ & 0.11 & - & 0.16 \\
\hline $\begin{array}{l}\text { Ratio of negative grid to beam current } \\
\text { Negative grid voltage, } V\end{array}$ & $\begin{array}{r}0.0035 \\
300\end{array}$ & $\begin{array}{r}0.0092 \\
510\end{array}$ & $\begin{array}{r}0.0037 \\
800\end{array}$ & $\begin{array}{r}0.0054 \\
330\end{array}$ \\
\hline Facility pressure, $\mathrm{Pa}$ & $1.3 \times 10^{-3}$ & $1.7 \times 10^{-3}$ & $3 \times 10^{-4}$ & $1.7 \times 10^{-3}$ \\
\hline Test time, hr & 4350 & 570 & 1110 & 957 \\
\hline Facility diameter, m & 2.5 & 7.6 & 3 & 4.6 \\
\hline Distance to target, $\mathrm{m}$ & 4.1 & 20 & 5 & 9.4 \\
\hline Target material & graphite & tank wall & aluminum & graphite \\
\hline
\end{tabular}

a Neutralizer power not included.

TABLE II.-XENON ION SPUTTERING OF STEEL WASHERS AT TARGET

\begin{tabular}{|l|c|c|}
\hline & Measurement & Calculated \\
\hline Ion current density, $\mathrm{A} / \mathrm{m}^{2}$ & - & 0.29 \\
Iron sputter yield, atoms/ion & & 2.18 \\
Mass loss rate, $\mathrm{kg} / \mathrm{m}^{2} \mathrm{~s}$ & $2.3 \times 10^{-7}$ & $3.7 \times 10^{-7}$ \\
Ion erosion depth, $10^{-6} \mathrm{~m}$ & 110 & 160 \\
\hline
\end{tabular}

Conditions: Xenon ions, beam voltage $=1530 \mathrm{~V}$, beam current $=3.19 \mathrm{~A}$

Test time $=957 \mathrm{hr}$, location of washers: $z=9.37 \mathrm{~m}, \mathrm{r}=0.46 \mathrm{~m}$. 
TABLE III.-SPUTTERED MATERIAL DEPOSITION AFTER 957 HR

1. Deposition on thruster face

a. Calculation of deposition from target

- Carbon mass flux $6.2 \times 10^{-10} \mathrm{~kg} / \mathrm{m}^{2} \mathrm{~s}$

- Film thickness $2.0 \times 10^{-6} \mathrm{~m}$

b. Calculation of deposition from walls

- Film thickness

- all stainless steel walls

$0.3 \times 10^{-6} \mathrm{~m}$

- all carbon walls

$0.1 \times 10^{-6} \mathrm{~m}$

c. Measured film thickness

$<5 \times 10^{-6} \mathrm{~m}$

2. Deposition on facility end-cap, $(z, r)=(0.8 \mathrm{~m}, 1.5 \mathrm{~m})$

a. Calculated film thickness from target deposition $2.2 \times 10^{-6} \mathrm{~m}$

b. Calculated film thickness from walls

- all stainless steel walls $0.4 \times 10^{-6} \mathrm{~m}$

- all carbon walls

$0.1 \times 10^{-6} \mathrm{~m}$

c. Measured film thickness $2.2 \times 10^{-6} \mathrm{~m}$

Parameters: $\quad 1530 \mathrm{eV}$ xenon ions, ion beam current $=3.19 \mathrm{~A}$.

$\mathrm{Z}_{\mathrm{T}}=9.37 \mathrm{~m}, \mathrm{R}=2.26 \mathrm{~m}$.

$\mathrm{n}=2, \ell=45, \mathrm{C}(2,45)=25$. 


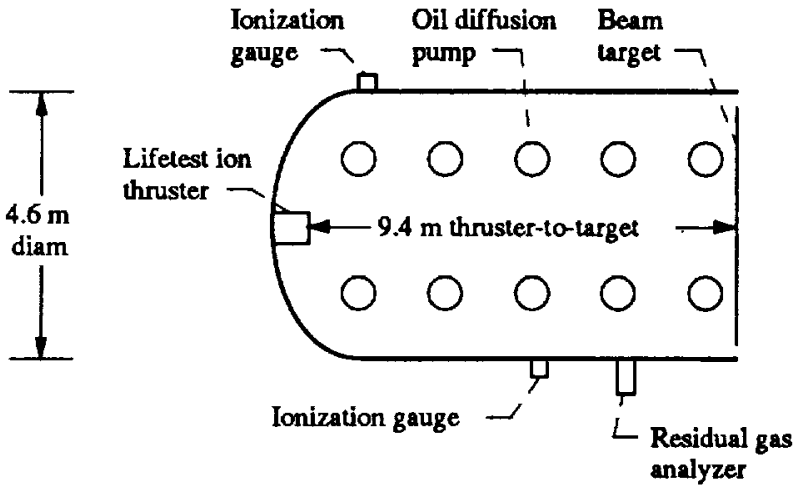

Figure 1.-Vacuum test facility (one-half of facility shown).

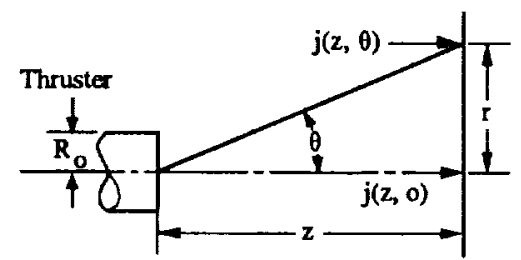

(a) Current density parameters-far-field probes.

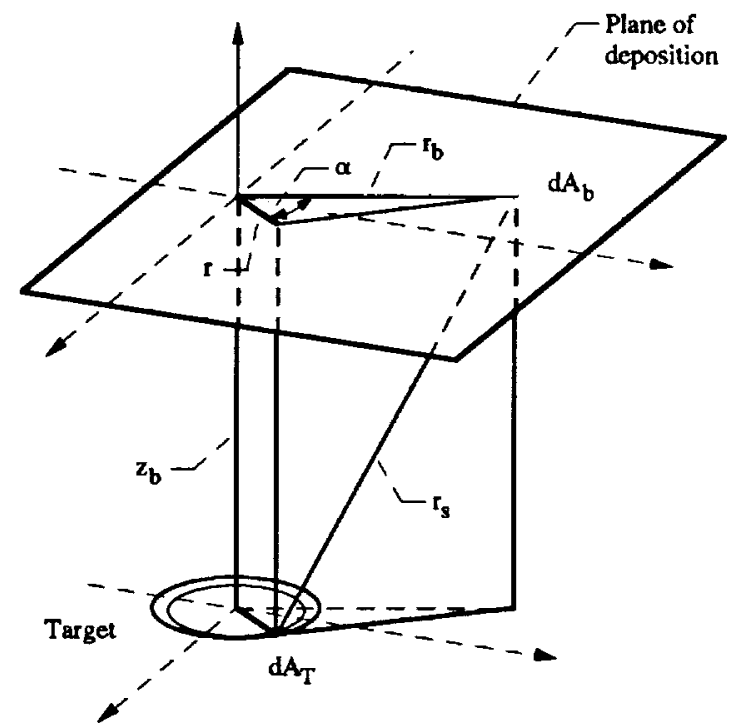

(b) Efflux from target to deposition plane.

Figure 2.-Geometries for ion current density and mass flux equations.

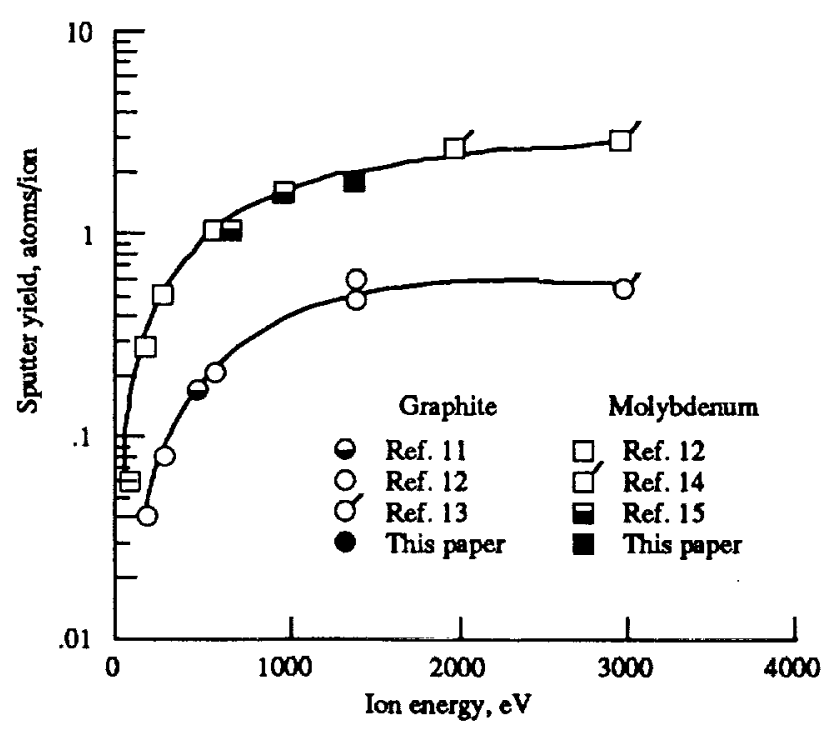

Figure 3.-Xenon ion sputter yield for carbon forms and molybdenum at normal ion incidence.

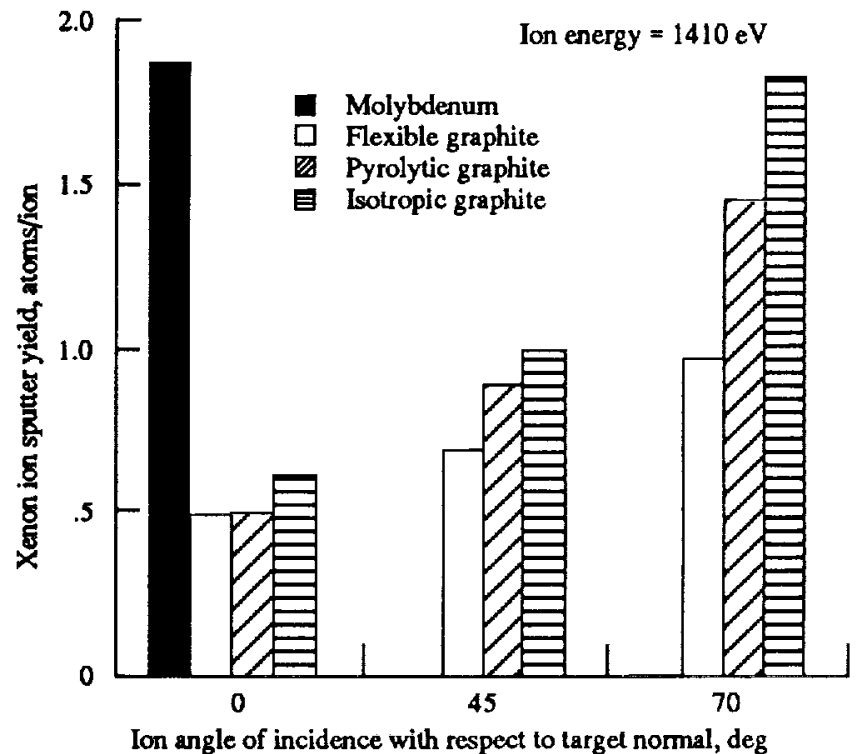

Figure 4.-Sputter yield as a function of ion angle of incidence. 


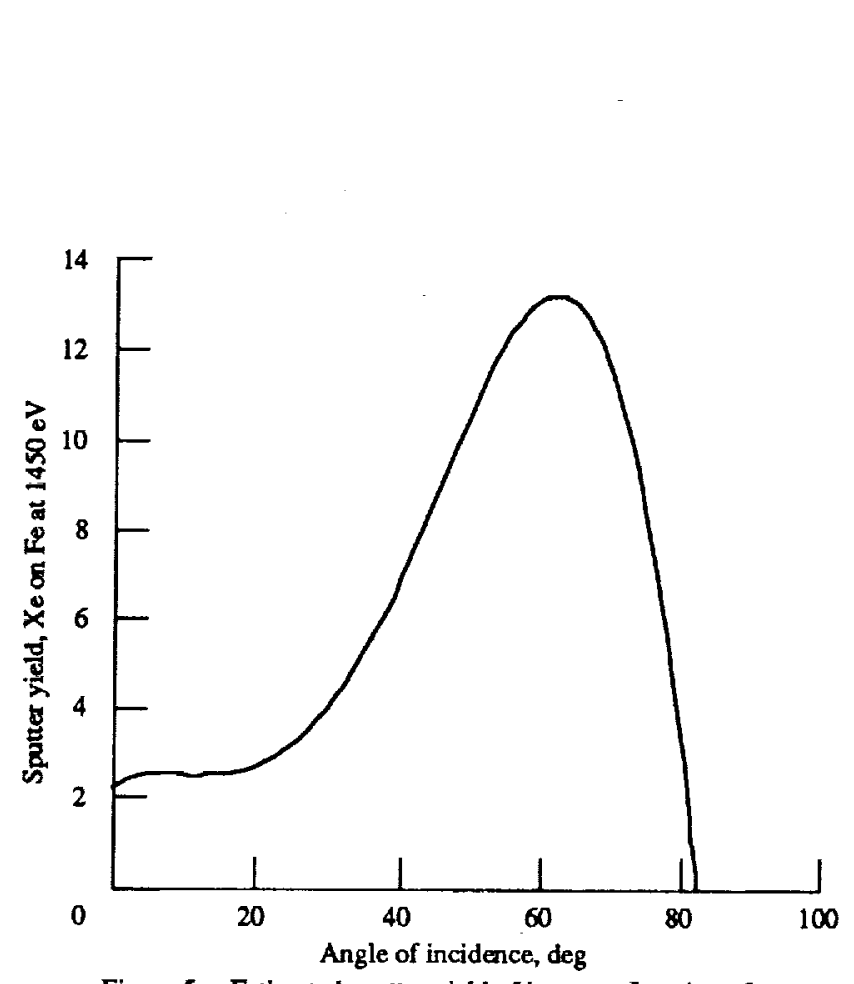

Figure 5.-Estimated sputter yield of iron as a function of angle of incidence of xenon ions at $1450 \mathrm{eV}$.

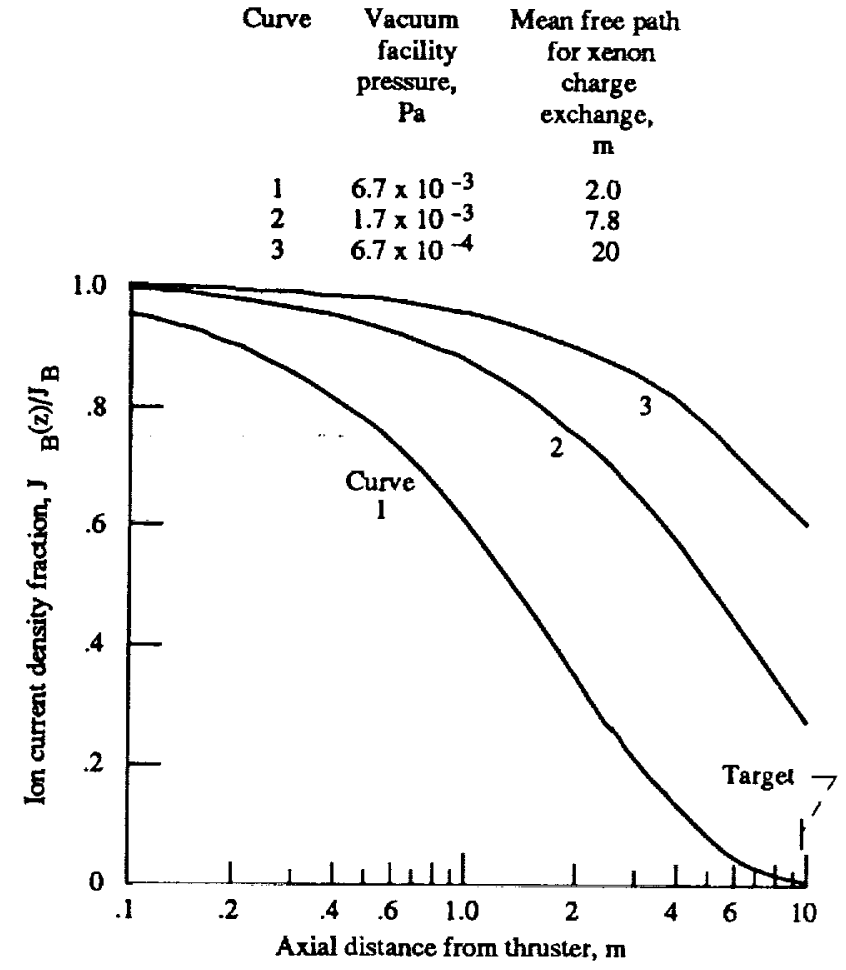

Figure 6. -Effect of charge exchange on ion current density fraction.

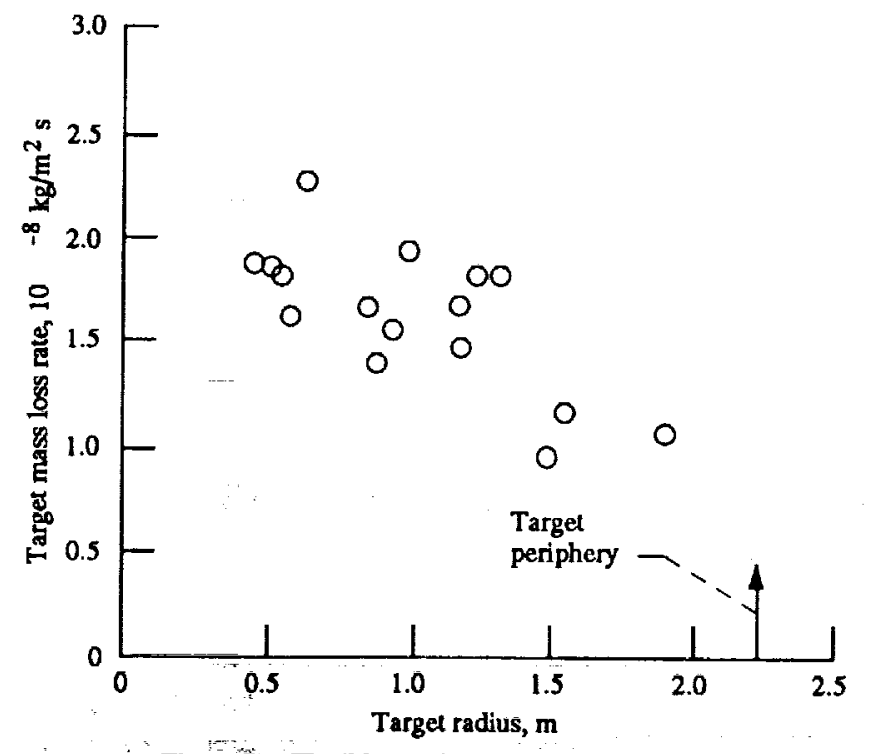

Figure 7.-Flexible graphite target mass loss rate. 


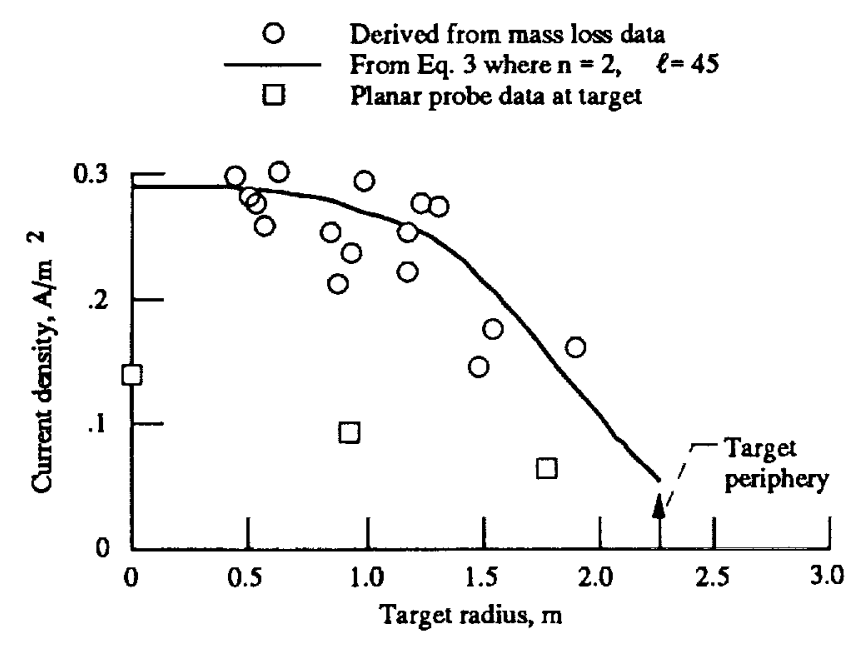

Figure 8.-Current density derived from target mass loss.
Derived from target mass loss data, Eqs. 4 and 15, $n=1, \ell=45$

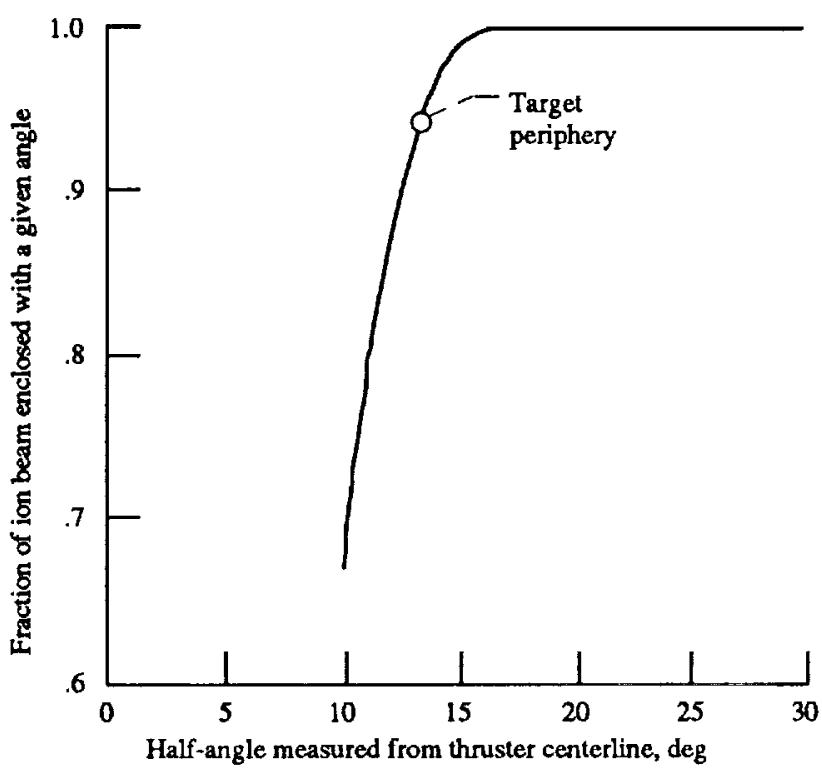

Figure 9.-Fraction of ion current enclosed within a given half angle.

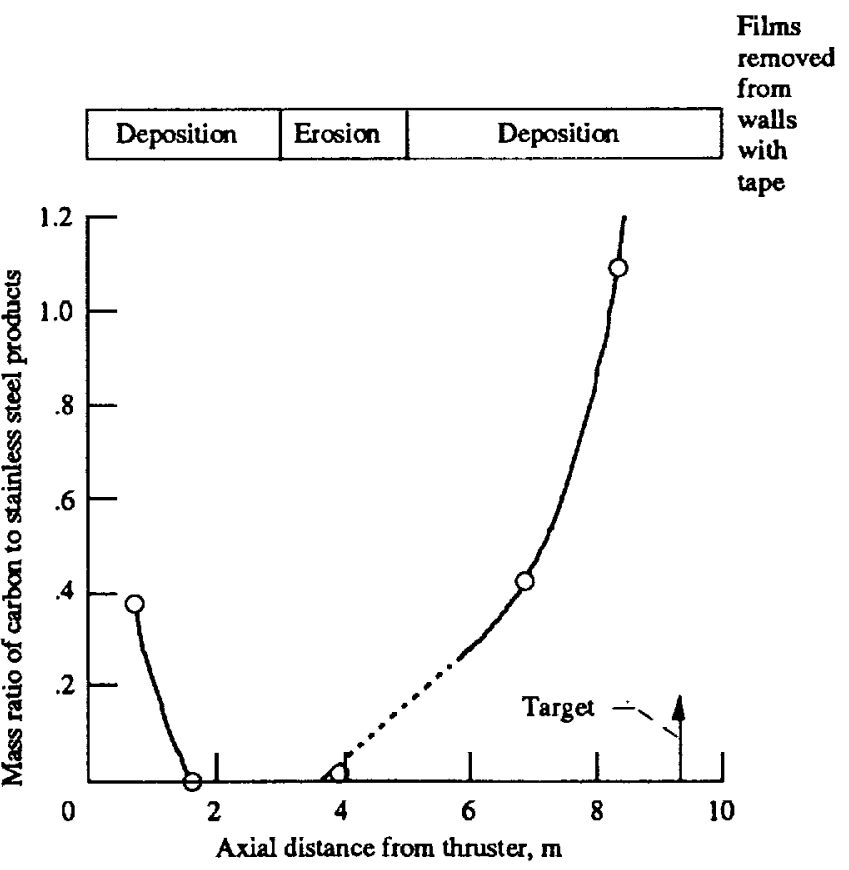

Figure 10.-Chemistry of spalled films from facility walls after $957 \mathrm{hr}$ test. 
Public reporting burden for this collection of information is estimated to average 1 hour per response, Including the time for reviewing instructions, searching existing data sources, gathering and maintaining the data needed, and complating and reviewing the collection of intormation. Send comments regarding this burden estimate or any other aspect of this collection of information, induding supgestions for reducing this burden, to Weshington Headquarters Services, Directorale for information Operations and Reports, 1215 Jefferson Davis Highway, Suito 1204, Arlington, VA 22202-4302, and to the Office of Management and Budget, Paperwork Reduction Project (0704-0188), Washington, DC 20503.

\begin{tabular}{|l|l|l}
\hline 1. AGENCY USE ONLY (Leave blank) & 2. REPORT DATE & $\begin{array}{r}\text { 3. AEPORT TYPE AND DATES COVERED } \\
\text { Technical Memorandum }\end{array}$ \\
\hline
\end{tabular}

4. TITLE AND SUBTITLE

Ion Beam Sputtering in Electric Propulsion Facilities

6. AUTHOR(S)

James S. Sovey and Michael J. Patterson

7. PERFORMING ORGANIZATION NAME(S) AND ADDRESS(ES)

National Aeronautics and Space Administration

Lewis Research Center

Cleveland, Ohio $44135-3191$

9. SPONSORING/MONITORING AGENCY NAMES(S) AND ADDRESS(ES)

National Aeronautics and Space Administration

Washington, D.C. 20546-0001
5. FUNDING NUMBERS

WU-506 - $42-31$

8. PERFORMING ORGANIZATION REPORT NUMBER

$E-6420$

11. SUPPLEMENTARY NOTES

Prepared for the 27th Joint Propulsion Conference cosponsored by AIAA, SAE, ASME, and ASEE, Sacramento, California, June 24-27, 1991. Responsible person, James S. Sovey, (216) 433-2420.

128. DISTRIBUTION/AVAILABILITY STATEMENT

Unclassified - Unlimited

Subject Category 20 12b. DISTRIBUTION CODE

\section{ABSTRACT (Maximum 200 words)}

Experiments were undertaken to determine sputter yields of potential ion beam target materials, to assess the impact of charge exchange on beam diagnostics in large facilities, and to examine material erosion and deposition after a $957 \mathrm{hr}$ test of a $5 \mathrm{~kW}$-class ion thruster. The xenon ion sputter yield of flexible graphite was lower than other graphite forms especially at high angles of incidence. Ion beam charge exchange effects were found to hamper beam probe current collection diagnostics even at pressures from 0.7 to $1.7 \mathrm{mPa}$. Estimates of the xenon ion beam envelope were made and predictions of the thickness of sputter deposited coatings in the facility were compared with measurements.

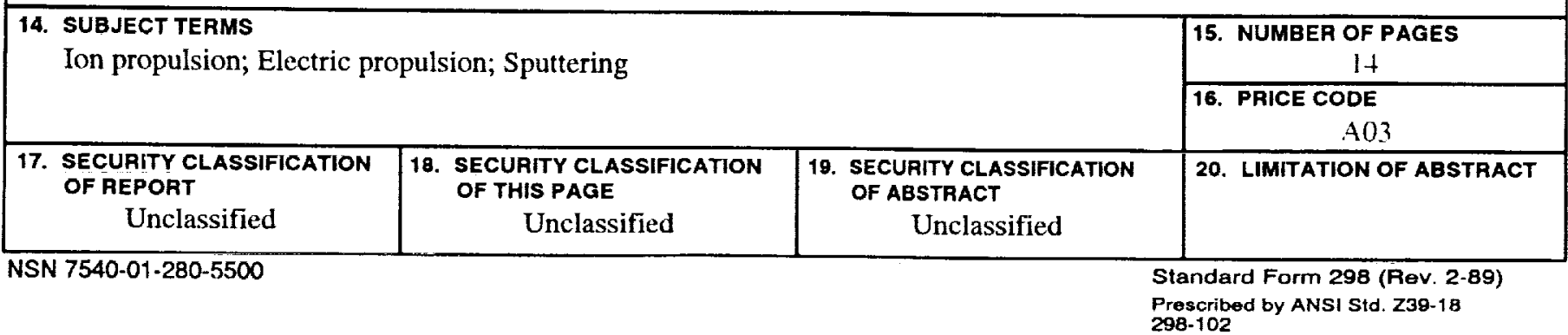

